Article

\title{
Improvement of AEP Predictions with Time for Swedish Wind Farms
}

\author{
Erik Möllerström * D, Sean Gregory and Aromal Sugathan
}

check for updates

Citation: Möllerström, E.; Gregory, S.; Sugathan, A. Improvement of AEP Predictions with Time for Swedish Wind Farms. Energies 2021, 14, 3475. https://doi.org/10.3390/en14123475

Academic Editor:

Mohamed Benbouzid

Received: 17 May 2021

Accepted: 8 June 2021

Published: 11 June 2021

Publisher's Note: MDPI stays neutral with regard to jurisdictional claims in published maps and institutional affiliations.

Copyright: (c) 2021 by the authors. Licensee MDPI, Basel, Switzerland. This article is an open access article distributed under the terms and conditions of the Creative Commons Attribution (CC BY) license (https:/ / creativecommons.org/licenses/by/ $4.0 /)$.
School of Business, Innovation and Sustainability, Halmstad University, P.O. Box 823, SE-301 18 Halmstad, Sweden; seangregoryv122@gmail.com (S.G.); aromal92@outlook.com (A.S.)

* Correspondence: erik.mollerstrom@hh.se

Abstract: Based on data from 2083 wind turbines installed in Sweden from 1988 onwards, the accuracy of the predictions of the annual energy production (AEP) from the project planning phases has been compared to the actual wind-index-corrected production. Both the electricity production and the predicted AEP come from Vindstat, a database that collects information directly from wind turbine owners. The mean error for all analyzed wind turbines was $13.0 \%$, which means that, overall, the predicted AEP has been overestimated. There has been an improvement of accuracy with time with an overestimation of $8.2 \%$ for wind turbines installed in the $2010 \mathrm{~s}$, however, the continuous improvement seems to have stagnated around 2005 despite better data availability and continuous refinement of methods. Dividing the results by terrain, the error is larger for wind turbines in open and flat terrain than in forest areas, indicating that the reason behind the error is not the higher complexity of the forest terrain. Also, there is no apparent increase of error with wind farm size which could have been expected if wind farm blockage effect was a main reason for the overestimations. Besides inaccurate AEP predictions, a higher-than-expected performance decline due to inadequate maintenance of the wind turbines may be a reason behind the AEP overestimations. The main sources of error are insecurity regarding the source of AEP predictions and the omission of mid-life alterations of rated power.

Keywords: energy assessment; Vindstat; AEP; WCP; wind power; Sweden

\section{Introduction}

Wind power is likely to play a key role when replacing traditional power production with renewable alternatives. When installing the large number of wind turbines needed for this transition, it will be a challenge to gain public acceptance. Wind turbines will probably to a large extent have to be located at inland sites, typically with lower overall wind speeds compared to coastal sites. This means lower margins and therefore increased demands for reliable prediction of the annual energy production (AEP) for planned wind power developments. The inland sites can often be of more complex terrain, for example forest, which also means greater uncertainty [1].

Sweden had an ambitious wind energy program with multi-megawatt prototypes built in the early 1980s [2]. Although Sweden today has no wind turbine industry, in 2019 wind power made up about $12 \%$ of the Swedish electricity production [3]. With Swedish nuclear reactors likely to be phased out in the coming decades and with the expected electrification of the transportation sector, the installation rate of power production is likely to increase. This also increases the demand for reliable and accurate AEP predictions, especially since most future wind energy developments are likely to be in forest terrain.

When developing a future wind farm, a crucial step is predicting the AEP, typically using wind-farm project planning software which for most cases uses a linear flow model (for more complex terrain, CFD models are recommended). The used model evaluates wind data (typically from wind measurement masts), which, if long-term correlated, can be used to predict the normal-wind-year AEP for a planned wind farm. From these predictions, a 
P50 value (50th percentile), which by definition is supposed to have a 50\% probability of exceeding the production for a normal-wind year in reality, can be acquired. According to the standard procedure [4], the predicted AEP (P50) is calculated as a mean value, which can be explained by the fact that the mean and median values coincide for a normal distribution, which over time is reasonable to assume for the AEP. From the P50 value and expected uncertainties of different parameters, other P-values can be estimated. The wind resource evaluation with subsequent $\mathrm{AEP}$ prediction is an uncertain process, and a thorough assessment of the uncertainty is critical for assessing the risk of a planned wind energy development [5].

It is reasonable to assume that the AEP prediction accuracy should improve with time. This because of improvements such as access to better long-term corrected wind data, more detailed terrain data, improved flow models with more advanced wind-shear calculation models, improved tools for sector-based zero-plane displacement, improved standards, refined measurement methods, and a better understanding of cold-climate effects. There are continuously new and improved methods being developed to improve AEP predictions, for example using refined wind speed probability distributions [6] or implementing artificial intelligence to improve power predictions $[7,8]$.

In a DNV GL report [9], a validation between AEP predictions and the actual production is presented for Great Britain, Ireland (Republic of Ireland and Northern Ireland), South Africa and UK offshore wind farms. For Great Britain, the AEP predictions had been overestimated by $3.1 \%$ based on data from 87 wind farms. Although based on a smaller amount of data, the other regions also displayed overestimations, Ireland, and South Africa with $4 \%$ to $5 \%$, whereas the UK offshore were only $0.4 \%$ under target. The AEP predictions were adjusted to correspond with the latest methodology, making the results valid for projects developed in 2019 independent of the construction year. According to the report, the overestimations are most likely due to shortcomings at the pre-construction energy-assessment stage. In [10], the neglect of the so-called wind-farm blockage effect (i.e., that not only downstream but also upstream turbines suffer from reduced wind speeds) is suggested to be a key reason for the overestimation of AEP predictions. Moreover, AEP predictions have been compared with production data for individual wind farms [11-13], and the uncertainty of wind turbine AEP predictions have been the subject of several studies [5,14-16].

Previously within the same project as this study but based on a smaller amount of wind turbine data, production data from numerous existing wind farms in Sweden were compared with the pre-construction AEP predictions and preliminary results were presented in [17] which showed a larger overestimation than for the British Isles and South Africa. However, in this continued study, a larger amount of wind turbines have been included and a more in-depth analysis is performed with the results divided on factors such as wind turbine manufacturer and wind farm size. This to broaden the understanding of the cause behind these overestimations for Swedish wind turbines, as well as further establishing them. The method used to calculate a normalized annual electricity yield to compare with AEP predictions is based on the method used by industry to make results comparable with other studies. In addition to the method in [17], wind turbine performance decline has here been accounted for since older wind turbines are included in this analysis. Time trends regarding year of installation have been analyzed to determine whether expected accuracy improvements with time can be observed. The results have been divided by the terrain type to indicate whether the accuracy is affected by the complexity of the terrain. There are few available studies on the accuracy of AEP predictions based on data from a large number of wind turbines and together with the previously published [17], this work is likely unique for the case of Sweden and adds to the general knowledge base of the performance of wind power AEP predictions. 


\section{Wind Turbine Production Data}

The data used in this study comes from the database Vindstat, which has been collecting production data, including downtime, from wind turbines in Sweden since 1988 [18]. The data from Vindstat have previously been used for an evaluation of the wind turbine performance decline in Sweden [19]. Vindstat membership have always been optional but most Swedish wind turbines were included until 2016 when the Swedish energy agency withdrew its financial support and Vindstat introduced a member fee. After this, several of the large wind turbine owners left Vindstat, limiting the wind turbines in the database to about half for subsequent periods. Besides production data, some general information about each wind turbine, such as the predicted AEP as reported by the owner, is included in Vindstat. This reported AEP is assumed to correspond to a normal wind year and come from the wind energy calculation from the planning phase.

For this study, all Vindstat reporting wind turbines that were still in operation in 1999 were used, in total comprising 2083 turbines. The production data between 1999-2020 was then analyzed. The geographical spread of the available turbines is illustrated in Figure 1. After excluding turbines according to a number of criteria (see "Section 3.3 Data exclusion"), the number of wind turbines was decreased to that listed in Table 1. Using satellite imagery, the number of wind turbines in each wind farm have been decided and the terrain have been divided into three types: open terrain, forest areas, and offshore, with the number of turbines in each category seen in Table 2.

Table 1. Vindstat data used for this study. The excluded data were removed according to "Section 3.3 Data Exclusion".

\begin{tabular}{ccc}
\hline & No Data Exclusion & with Data Exclusion \\
\hline Wind turbines & 2083 & 1723 \\
Total capacity (GW) & 3.28 & 2.52 \\
Observations (months) & 235,903 & 132,568 \\
\hline
\end{tabular}

Table 2. Error of AEP predictions compared to the production-based WCP for the full data set of the study and divided into terrain type, manufacturer, wind farm size, and decade of installation.

\begin{tabular}{cccccc}
\hline & & Result & \multicolumn{3}{c}{ Data } \\
\hline \multirow{2}{*}{ All data } & & Error (\%) & Turbines & Power (MW) & Observations \\
\hline \multirow{3}{*}{ Terrain } & Flat & 13.0 & 1723 & 2524 & 132,568 \\
& Forestall & 13.4 & 954 & 1065 & 84,388 \\
& Offshore & 6.1 & 677 & 1263 & 41,473 \\
Manuf. & Vestas & 11.1 & 92 & 196 & 6707 \\
& Enercon & 12.1 & 441 & 1221 & 67,643 \\
& Other & 17.3 & 448 & 652 & 37,544 \\
Farm size & Single & 14.3 & 380 & 651 & 37,544 \\
& $2-4$ & 13.2 & 579 & 297 & 34,035 \\
& $5-10$ & 12.5 & 388 & 648 & 49,248 \\
& $>10$ & 11.8 & 376 & 850 & 29,577 \\
Install. & $1990 \mathrm{~s}$ & 19.8 & 435 & 199 & 43,708 \\
Decade & $2000 \mathrm{~s}$ & 13.2 & 590 & 794 & 52,876 \\
& $2010 \mathrm{~s}$ & 8.2 & 689 & 1529 & 35,583 \\
\hline
\end{tabular}




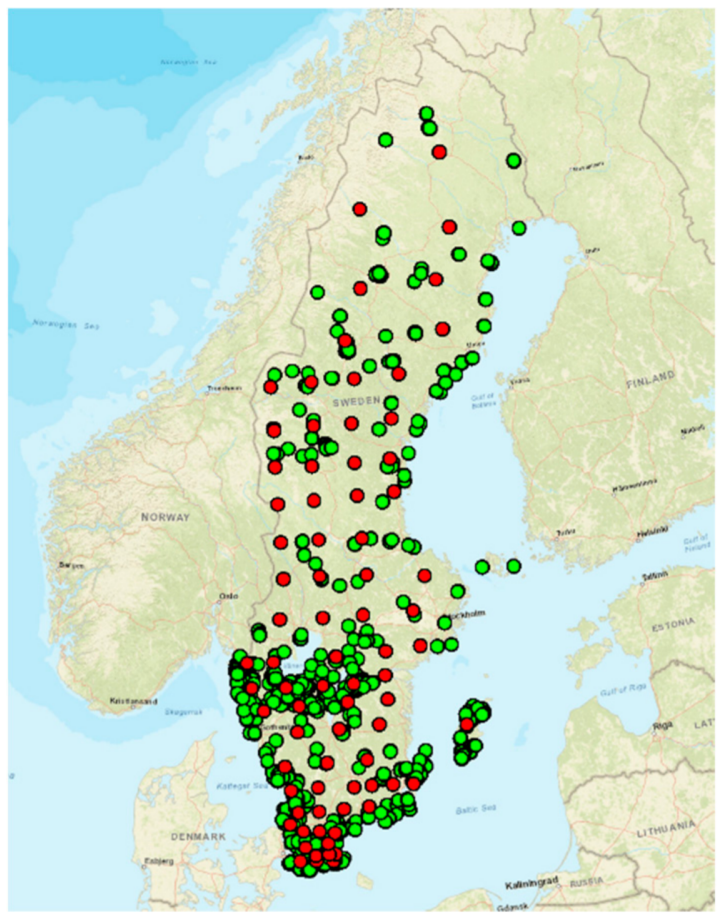

Figure 1. A map of the locations of wind turbines included in this study (green) and index sites used for normal wind-year normalization (red); see Section 3.2.

\section{Methods}

To be comparable with the given AEP predictions (P50-values), the wind turbine production data must be normalized to correspond to the wind energy available for a normal wind year and the availability counted on for the P50 prediction. The production data presented per month were recalculated to wind-index corrected annual production (WCP) and compared to the P50-values according to the following subsections.

\subsection{Normalization to Wind Turbine Availability, Wind Turbine Performance Decline and Transformer Efficiency}

The AEP (P50) value corresponds to the availability that the owner can count on, i.e., the manufacturer-guaranteed availability, which typically is $97 \%$ [15]. The time-based availability, i.e., the percentage of a given period that a wind turbine is available for operation, can for a given month be calculated as:

$$
A_{t}=\frac{T_{m}-T_{d}}{T_{m}}
$$

where $T_{m}$ is the total number of hours for the month and $T_{d}$ is the downtime hours for the same month. Moreover, in a number of studies, a performance decline with age has been established [19-26], with [19], partly based on the same Vindstat data as used in this study, showing an average annual performance decline of $0.1 \%$, counted as capacity factor percentage points and excluding increase of downtime. Assuming a capacity factor of $1 / 3$, this means $0.3 \%$ when considering AEP loss. To make results comparable for wind turbines with various mean time difference between the installation year and the time period of analyzed data, this must be accounted for. Using the yearly performance decline factor from [19], $d_{y}=0.003$, and using the age of the wind turbine at the time of the analyzed month, $A$, an age performance factor can be set as:

$$
F_{\text {age }}=1+d_{y}(10-A)
$$


where we assume that the AEP prediction should be valid over an expected life length of 20 years. The availability for the month can then be used to calculate the electricity yield normalized for the typical industry standard availability $\left(A_{s t d}\right)$ of $97 \%$ :

$$
E_{a}=\frac{E \cdot A_{\text {std }} \cdot \eta_{t}}{A_{t} \cdot F_{\text {age }}},
$$

where $E$ is the generated electricity for the month, and $\eta_{t}$ is the transformer efficiency, which have to be accounted for since the AEP prediction refers to the electricity measured at the grid connection point. The transformer efficiency is set to $99 \%$, which is typical for Swedish AEP calculations for modern wind turbines.

\subsection{Wind Index Correction and Comparison with Predicted AEP}

Due to the interannual variations of wind speed, the typically available short-term wind measurement data for calculating a predicted annual electricity yield of a proposed wind turbine, must be correlated with a long-term wind dataset [27]. The insecurity of the correlation may surpass that of the confirmation between the data and a normal wind year for a sufficiently long time series [28]. However, when comparing different wind turbines, they must then have data for the same sufficiently long time period. In this study the available time periods differ between different wind turbines, which means that the production data must be individually correlated before comparing.

The normalization was performed with monthly correlation indices for 77 sites (see Figure 1 for site locations) spread across Sweden. The correlation indices were calculated from the ERA5T reanalysis, which has shown to perform well for the often complex-terrain sites of wind turbines in Sweden [29]. For each site, the index corresponds to the wind energy at $100 \mathrm{~m}$ above ground for the actual month, compared to the wind energy for the same month for a normal wind year. The mean distance between a wind turbine and its closest index site was $24 \mathrm{~km}$. The yearly mean values of the 77 indices counted together can be seen in Figure 2. For an individual wind turbine, all monthly production data normalized for availability $\left(E_{a}\right)$ were plotted against the corresponding (i.e., same month and for the index site closest to the wind turbine) correlation indices $\left(I_{n}\right)$. An example of this can be seen in Figure 3. From a linear regression line, the wind-indexnormalized production per month $\left(E_{n}\right)$ could then be attained for $I_{n}=1$ and thereafter the wind-index-corrected annual production $(W C P)$ could be calculated as:

$$
W C P=12 \cdot E_{n}
$$

The error between the real-life production $W C P$ and the from the project-developing phase predicted AEP (P50) can then calculated as:

$$
\text { error }=\frac{P 50-W C P}{W C P}
$$

A positive error means that the AEP-prediction was an overestimation of the actual electricity production, whereas a negative error means an underestimation. To evaluate the magnitude of the error rather than the placing, an absolute error could have been used instead. However, since the predicted AEP reported to the Vindstat database for some cases was presented as a fraction of the AEP for an entire wind farm, the mean absolute error is enlarged, and was therefore not used in this study. 


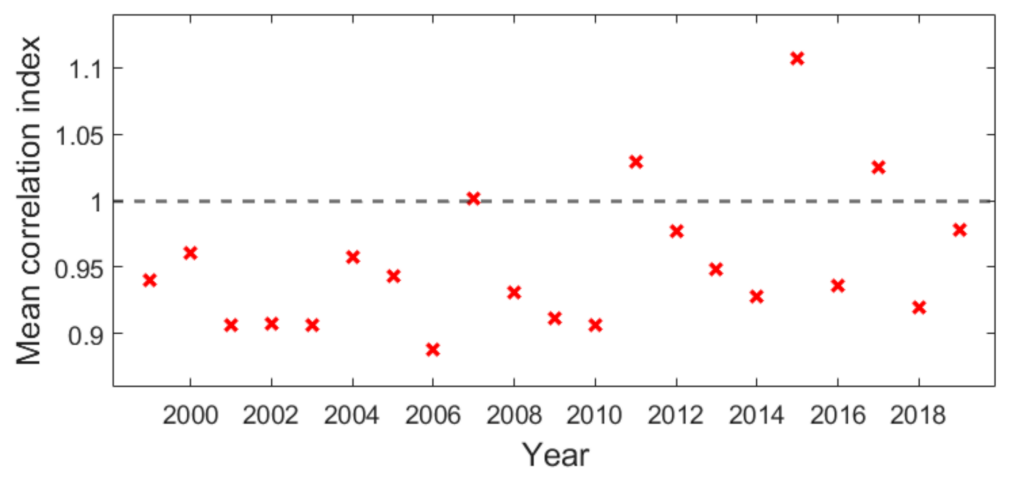

Figure 2. Yearly mean of all ERA5T correlation indices for the 77 sites.

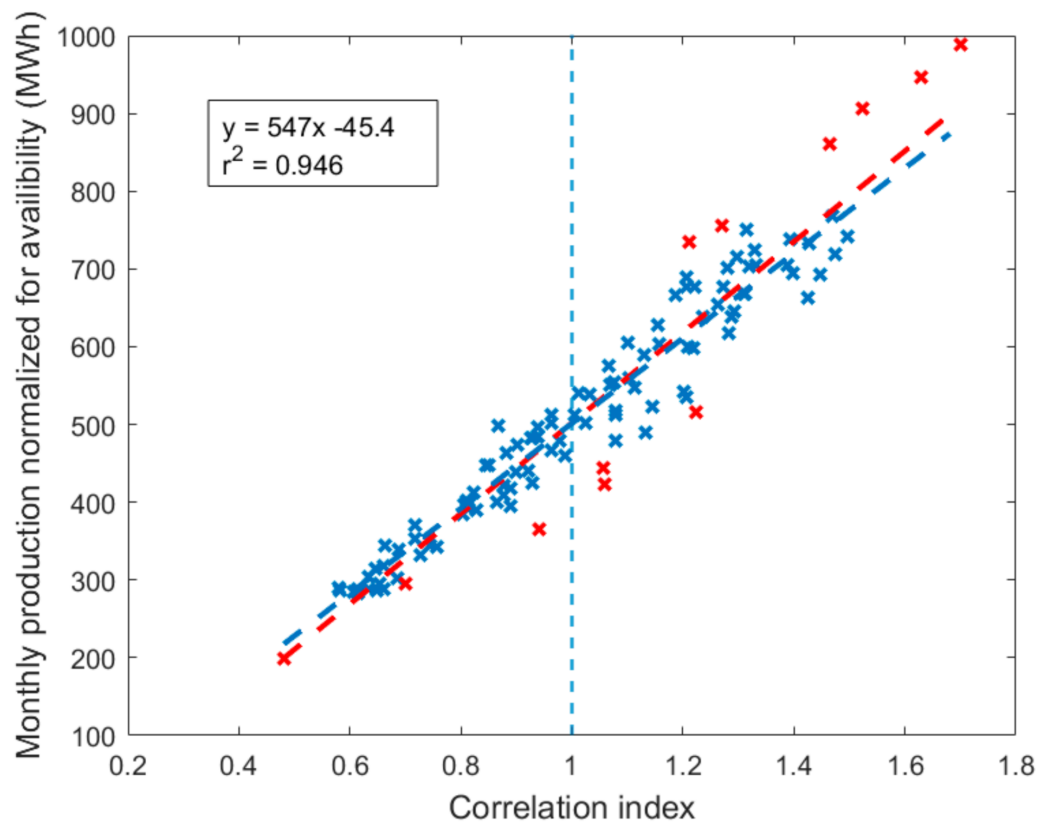

Figure 3. The production values (MWh/month) can be seen plotted against the corresponding (same month and closest index site) ERA5T correlation index. The red values have been excluded by the WCP filter.

\subsection{Data Exclusion}

To remove Vindstat reporting errors, months for which the sum of the downtime and the reported generator operation time were greater than the total hours of that month were excluded from further analysis. Months with availability under $90 \%$ were also excluded. To avoid the influence of corrupted data, the outliers in the production-index plot had to be removed. This was done with a WCP filter set to $\pm 15 \%$ where the index-normalized monthly production was compared to the WCP and excluded according to:

$$
0.85 \cdot W C P>12 \cdot \frac{E_{a}}{I_{n}}>1.15 \cdot W C P
$$

The WCP was recalculated without the filtered values (see Figure 3). To further exclude unrepresentative wind turbines from the study, turbines with fewer than 12 remaining month-production values or with coefficient of determination $\left(r^{2}\right)$ below 0.85 , were also removed. 


\section{Results and Discussion}

For each wind turbine, the errors of the pre-construction AEP predictions compared to production-based WCP were calculated by normalizing and recalculating the monthly wind power production data according to Equations (1)-(4) and comparing it to the given AEP prediction (P50) in Equation (5). The mean error based on all wind turbines in the study was $13.0 \%$, which means that overall, the predicted AEP of the studied wind turbines was overestimated. The mean overestimation is larger than the $7.1 \%$ previously shown for the same dataset but then only looking at wind turbines with a rated power of at least 1.8 MW and installed after 2005, and without taking turbine performance decline into consideration [17]. The results also emphasize the larger error for Swedish wind power projects compared to the overestimations previously shown for the British Isles and South Africa [9].

In Table 2, the error based on all wind turbines is shown, divided into terrain type, manufacturer, wind farm size, decade of installation, and the number of wind turbines in the wind farm can be seen. The error is slightly larger for the less-complex flat terrain than for forestall terrain which indicates that a higher complexity, such as for the forest terrain, is not the main reason behind the error. The accuracy was higher for offshore turbines, but this is based on a relatively small amount of data. Dividing the error between the most common wind turbine manufacturers in the analyzed data, the error was slightly larger for Enercon turbines than for Vestas turbines, although both cases were more accurate than turbines of other brands. Regarding wind farm size, the accuracy was higher with more turbines.

In Table 2, the error divided on installation decade can also be seen and although still overestimated, the error was overall smaller for 2010s with 8.2\%. In Figure 4, the error divided by the wind turbine installation year can be seen. The AEP predictions have with the exceptions of 2013 and 2016 been overestimated (only four wind turbines installed in 2016). Although the accuracy can be said to have improved from 1990 until around 2005, thereafter it has stagnated. The early improvement was anticipated due to the relatively small-scale wind power projects in the early 1990s and the successive implementation of the usage of wind-farm project planning software and usage of more reliable wind and terrain data. The accuracy was highest for wind turbines installed between 2011 and 2013 which was followed by a drop to the accuracy level of 2002 in 2014 and 2015. The lack of improved accuracy in recent years is contradictory keeping in mind the continuous refinements of the AEP predictions, for example access to better long-term corrected wind data, more detailed terrain data, improved flow models (including improved wind-shear calculation models), improved tools for sector-based zero-plane displacement, improved standards, refined measurement methods and a better understanding of cold-climate effects.

In Figure 5, the development of the AEP prediction accuracy over time can be seen, divided into terrain type, manufacturer, and wind farm size. In Figures 6-8, the same plots can be seen with standard deviation and number of wind turbines for each year. For terrain, installations before 2004 had a higher accuracy for flat terrain than for forestall terrain while installations in forestall have been slightly more accurate thereafter. The improvement over time for installations in forestall terrain is probably an effect of improved models and data used for the AEP estimation. Furthermore, projects in the forest are more likely to be based on on-site, hub-height wind measurements, which limits the insecurity. For the influence on manufacturer, projects with Vestas turbines had large overestimations around the year 2000 but have otherwise had a higher accuracy than for the case of Enercon. Dividing the results on wind turbine size, there are no apparent difference in accuracy between farm sizes, with wind farms of more than 10 turbines having the highest overall accuracy. If wind-farm blockage effect was a main contributor to the overestimations of AEP predictions, an increased overestimation with farm size could have been anticipated.

Besides inaccuracy of the AEP predictions, inadequate maintenance of the wind turbines and thus a higher-than-expected performance decline may be a reason behind the overestimations of AEP. The assumption that the predicted AEP, reported by the wind 
turbine owners to the Vindstat database, comes from the actual project planning phase adds some uncertainty to the results. Moreover, for some turbines, the rated power, or other operational strategies, may have been altered after installation. For example, the turbine power may have been downrated due to structural issues or uprated due to a manufacturer performance upgrade release. This will affect the comparison between the AEP predictions, which were made for the original rated power, and the production data after the change in rated power. A more detailed study, although based on fewer data, could be carried out for a number of projects by gathering individual AEP prediction reports from the project planning phase and accounting for mid-life alterations of rated power.

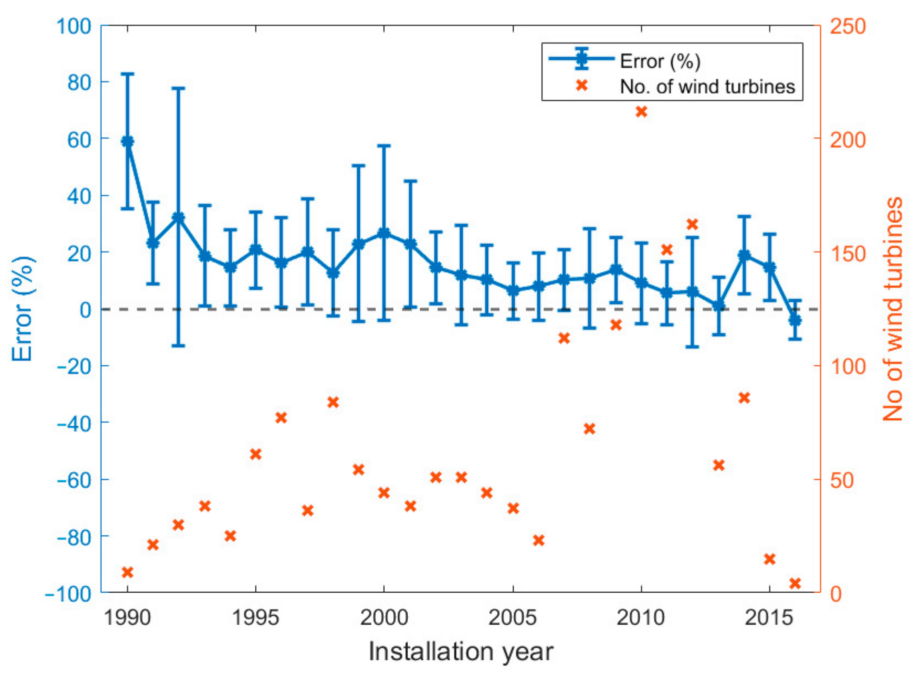

Figure 4. Error of AEP predictions depending on the installation year plotted with the standard deviation (blue) and number of wind turbines (red).
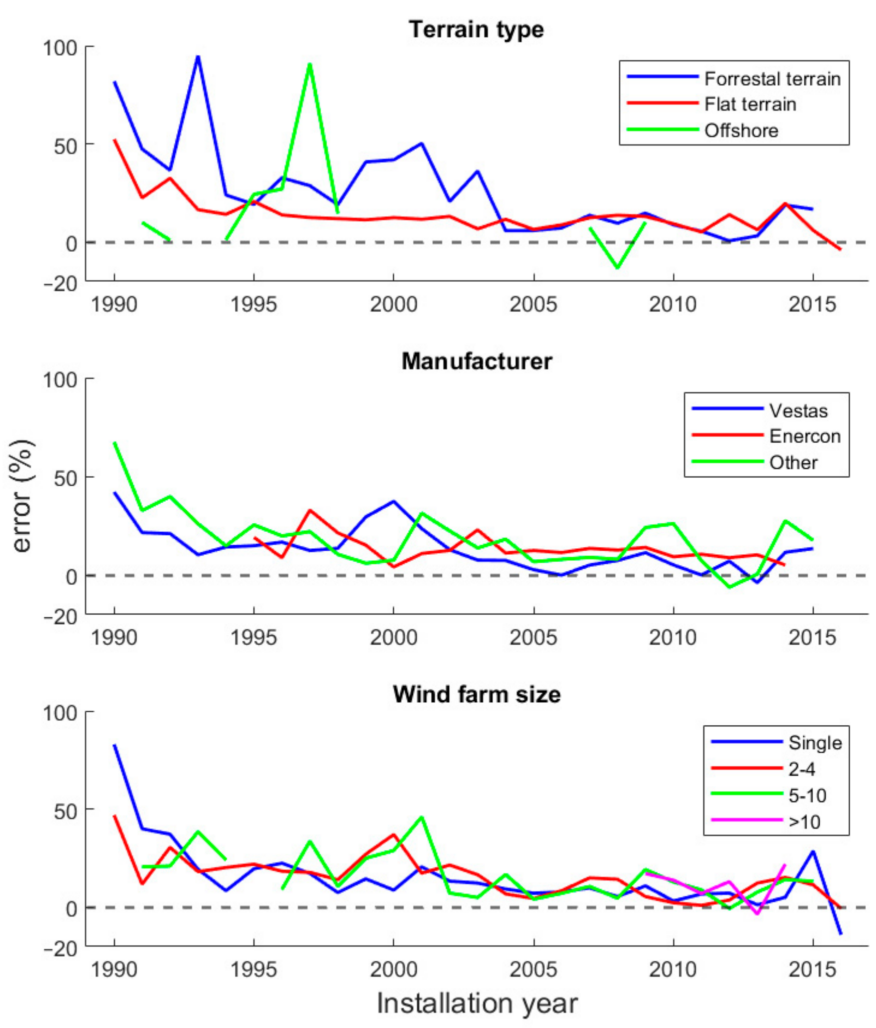

Figure 5. The time development of the AEP prediction accuracy divided on terrain type, manufacturer, and wind farm size. 

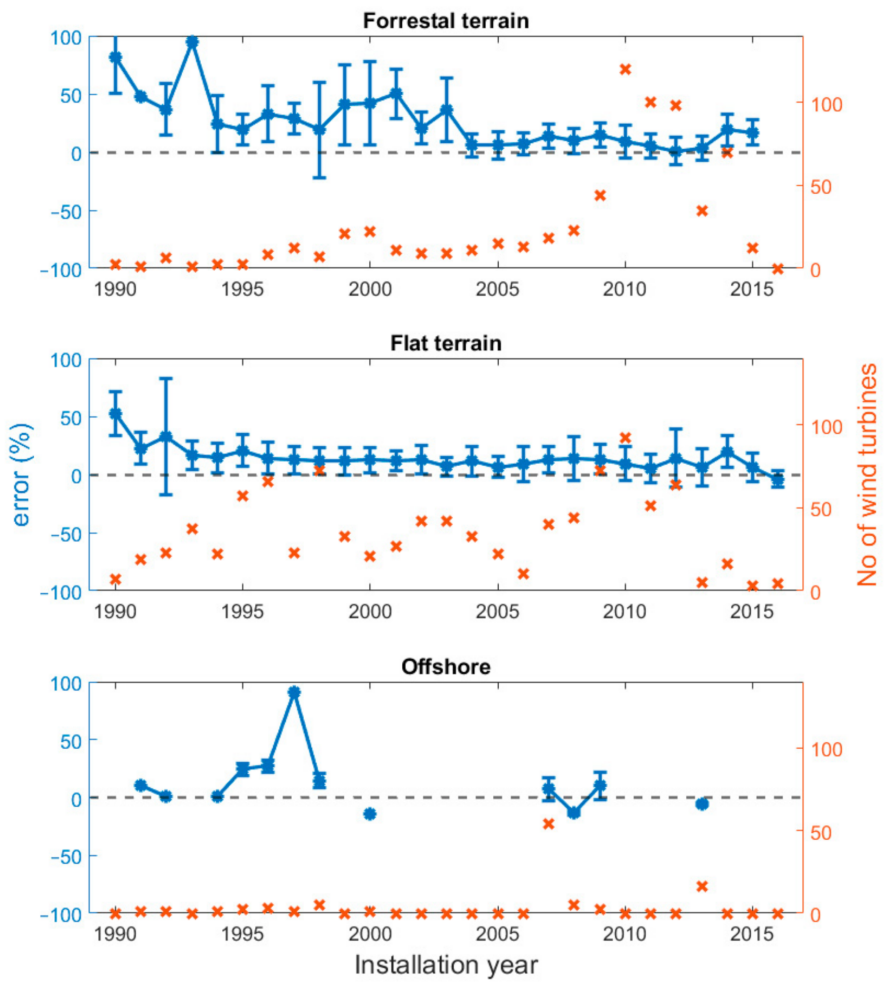

Figure 6. The time development of the AEP prediction accuracy divided on terrain type with number of wind turbines for each year.
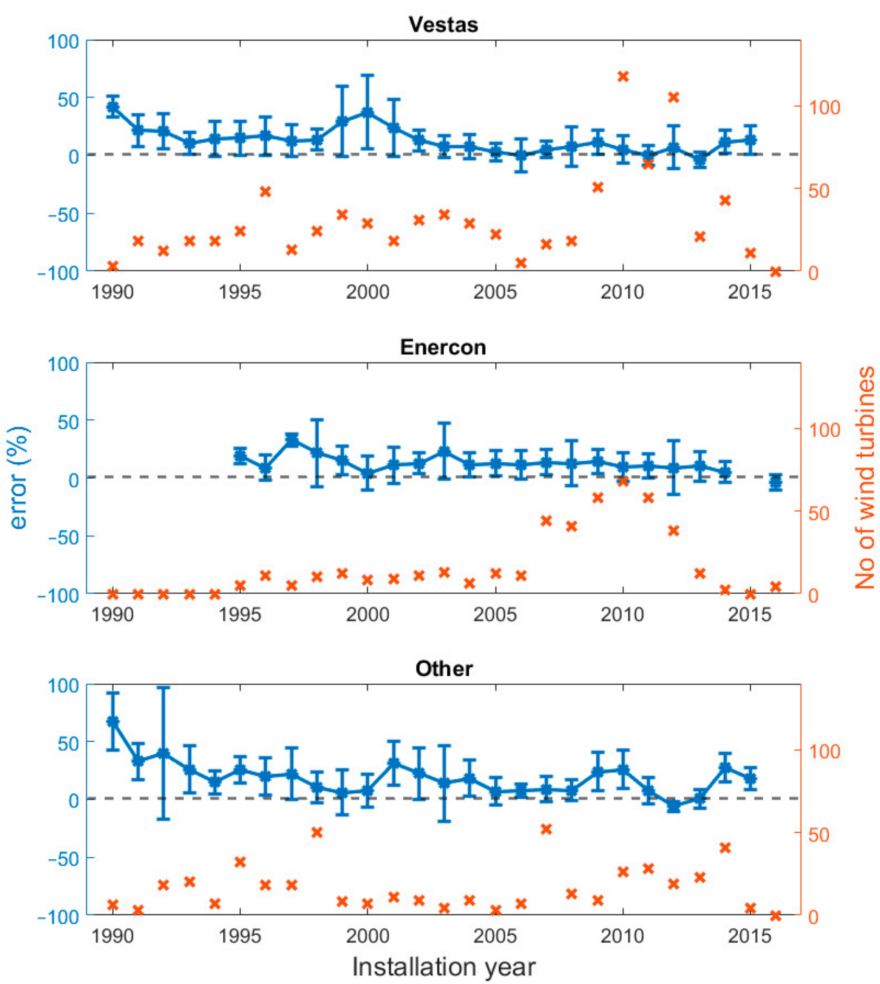

Figure 7. The time development of the AEP prediction accuracy divided on manufacturer with number of wind turbines for each year. 

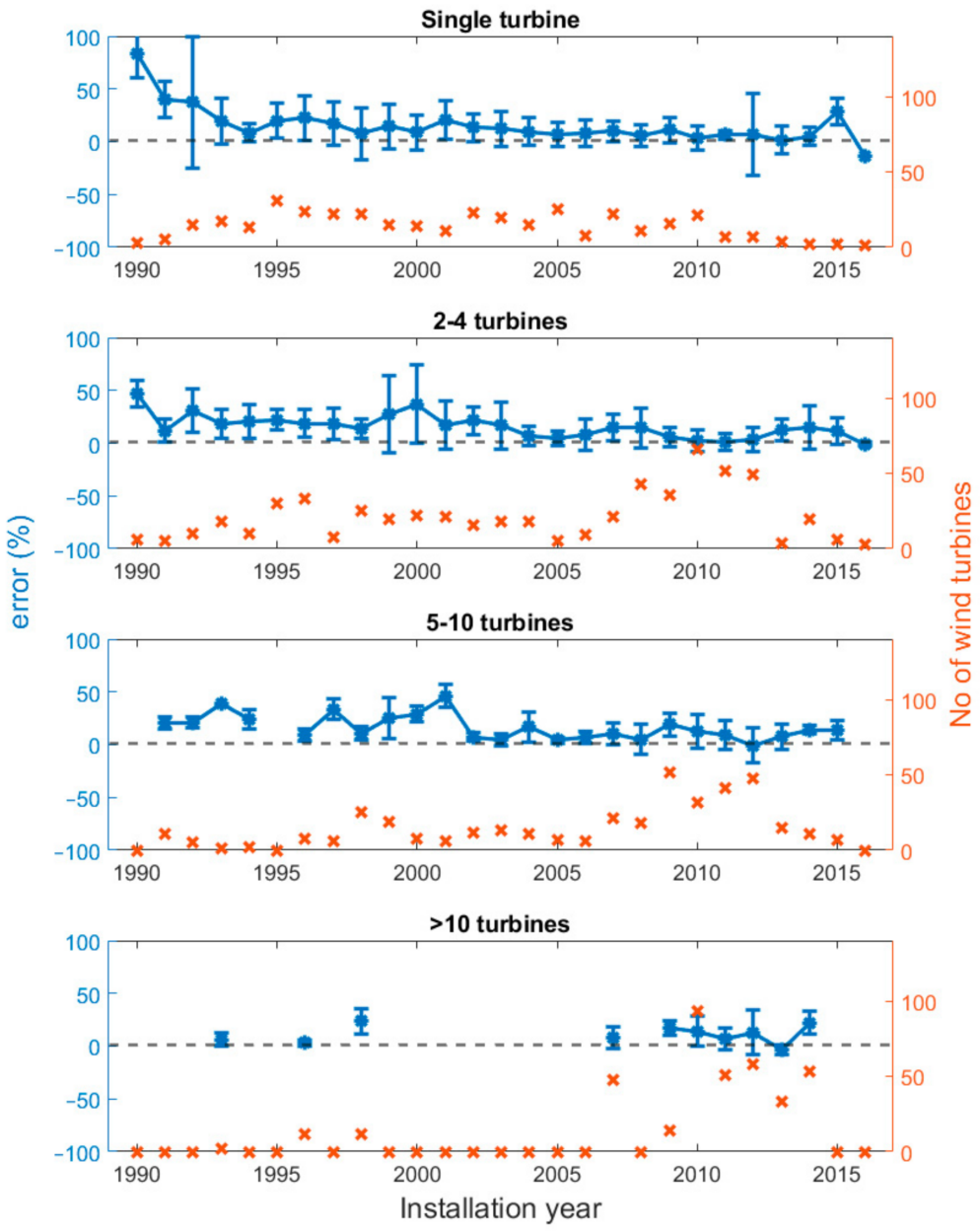

Figure 8. The time development of the AEP prediction accuracy divided on wind farm size with number of wind turbines for each year.

\section{Conclusions}

Based on evaluation of wind turbine production data between 1999 and 2020 and comparing with the wind-index-corrected and availability-corrected production, the AEP predictions from the planning phase of Swedish wind turbines was overestimated, on average, with $13.0 \%$. There has been an improvement of accuracy with the decades with an overestimation of $8.2 \%$ for wind turbines installed in the 2010 s. However, the continuous improvement seems to have stagnated around 2005, whereafter no general improvement can be seen, which could have been expected due to better data availability and continuous refinement of methods. As previously indicated in a preliminary study based on a limited part of the same data set as this study, the overestimation is higher than the previously shown overestimated AEP predictions for wind farms in the British Isles and South Africa. Dividing the results by the type of terrain, the error is larger for open terrain than for forest areas, indicating that a higher complexity, such as for forest terrain, is not a major contributor to the error. Also, there is no apparent increase of error with wind farm size which could have been expected if wind farm blockage effect was a main reason for the overestimations. Besides inaccurate AEP predictions, a higher-than-expected performance decline due to inadequate maintenance of the wind turbines may be a reason behind the AEP overestimations. A major source of insecurity is whether the AEP predictions reported from the wind turbine owners to the Vindstat database comes from the actual wind energy calculation from the planning phase. Moreover, possible mid-life alterations of rated power may have affected the comparison between the predicted AEP and the production data. 
Author Contributions: Conceptualization, E.M.; methodology, E.M.; formal analysis, E.M., S.G. and A.S.; writing—original draft preparation, E.M.; writing—review and editing, E.M., S.G. and A.S.; visualization, E.M.; project administration, E.M. All authors have read and agreed to the published version of the manuscript.

Funding: This research received no external funding.

Institutional Review Board Statement: Not applicable.

Informed Consent Statement: Not applicable.

Data Availability Statement: Not applicable.

Acknowledgments: Special thanks to Daniel Lindholm from Stena Renewable, Nils-Erik Carlstedt from Vindstat, Fredric Ottermo from Halmstad University and Erik Edelönn.

Conflicts of Interest: The authors declare no conflict of interest.

\section{References}

1. Enevoldsen, P. Onshore wind energy in Northern European forests: Reviewing the risks. Renew. Sustain. Energy Rev. 2016, 60, 1251-1262. [CrossRef]

2. Möllerström, E. Wind Turbines from the Swedish Wind Energy Program and the Subsequent Commercialization Attempts-A Historical Review. Energies 2019, 12, 690. [CrossRef]

3. Energimyndigheten, Energiläget i Siffror 2021. 2021. Available online: http://www.energimyndigheten.se/statistik/energilaget/ (accessed on 30 March 2021).

4. IEC 61400-12-1: Wind Turbines Part 12-1: Power Performance Measurements of Electricity Producing Wind Turbines, 1st ed.; The International Electrotechnical Commission (IEC): Geneva, Switzerland, 2005; Volume 12.

5. Lackner, M.A.; Rogers, A.L.; Manwell, J.F. Uncertainty analysis in MCP-based wind resource assessment and energy production estimation. J. Sol. Energy Eng. 2008, 130. [CrossRef]

6. Wacker, B.; Seebaß, J.V.; Schlüter, J.C. A modular framework for estimating annual averaged power output generation of wind turbines. Energy Convers. Manag. 2020, 221, 113149. [CrossRef]

7. Nielson, J.; Bhaganagar, K.; Meka, R.; Alaeddini, A. Using atmospheric inputs for Artificial Neural Networks to improve wind turbine power prediction. Energy 2020, 190, 116273. [CrossRef]

8. Neshat, M.; Nezhad, M.M.; Abbasnejad, E.; Mirjalili, S.; Groppi, D.; Heydari, A.; Tjernberg, L.B.; Garcia, D.A.; Alexander, B.; Shi, Q. Wind turbine power output prediction using a new hybrid neuro-evolutionary method. Energy 2021, 229, 120617. [CrossRef]

9. DNV GL Energy Production Assessment Validation; DNV GL-Energy: Bristol, UK, 2019.

10. Bleeg, J.; Purcell, M.; Ruisi, R.; Traiger, E. Wind farm blockage and the consequences of neglecting its impact on energy production. Energies 2018, 11, 1609. [CrossRef]

11. Ju, B.; Jeong, J.; Ko, K. Assessment of Wind Atlas Analysis and Application Program and computational fluid dynamics estimates for power production on a Jeju Island wind farm. Wind Eng. 2016, 40, 59-68. [CrossRef]

12. Han, S.; Gao, L.; Liu, Y.; Yang, W. Post evaluation of wind resource assessment and micro-siting. J. Power Energy Eng. 2014, 2, 288-296. [CrossRef]

13. Mortensen, N.G.; Nielsen, M.; Jørgensen, H.E. Comparison of Resource and Energy Yield Assessment Procedures 2011-2015: What Have we Learned and What Needs to be Done? EWEA Annual Conference and Exhibition 2015; European Wind Energy Association (EWEA): Brussels, Belgium, 2015.

14. Murcia, J.P.; Réthoré, P.-E.; Hansen, K.S.; Natarajan, A.; Sørensen, J.D. A New Method to Estimate the Uncertainty of AEP of Offshore Wind Power Plants Applied to Horns Rev 1; EWEA Annual Conference and Exhibition 2015; European Wind Energy Association (EWEA): Brussels, Belgium, 2015; pp. 161-165.

15. Jung, S.; Vanli, O.A.; Kwon, S.-D. Wind energy potential assessment considering the uncertainties due to limited data. Appl. Energy 2013, 102, 1492-1503. [CrossRef]

16. Rodríguez, O.; del Rio, J.A.; Jaramillo, O.A.; Martínez, M. Wind power error estimation in resource assessments. PLoS ONE 2015, 10, e0124830. [CrossRef]

17. Möllerström, E.; Lindholm, D. Evaluation of AEP Predictions for Commercial Wind Farms in Sweden. Appl. Sci. 2020, 10, 7995. [CrossRef]

18. Vindstat Database. Available online: http:/ / www.vindstat.nu/ (accessed on 9 June 2021).

19. Olauson, J.; Edström, P.; Rydén, J. Wind turbine performance decline in Sweden. Wind Energy 2017, 20, 2049-2053. [CrossRef]

20. Staffell, I.; Green, R. How does wind farm performance decline with age? Renew. Energy 2014, 66, 775-786. [CrossRef]

21. Germer, S.; Kleidon, A. Have wind turbines in Germany generated electricity as would be expected from the prevailing wind conditions in 2000-2014? PLoS ONE 2019, 14, e0211028. [CrossRef]

22. Hamilton, S.D.; Millstein, D.; Bolinger, M.; Wiser, R.; Jeong, S. How does wind project performance change with age in the United States? Joule 2020, 4, 1004-1020. [CrossRef] 
23. Byrne, R.; Astolfi, D.; Castellani, F.; Hewitt, N.J. A Study of Wind Turbine Performance Decline with Age through Operation Data Analysis. Energies 2020, 13, 2086. [CrossRef]

24. Astolfi, D.; Byrne, R.; Castellani, F. Analysis of Wind Turbine Aging through Operation Curves. Energies 2020, 13, 5623. [CrossRef]

25. Astolfi, D.; Byrne, R.; Castellani, F. Estimation of the Performance Aging of the Vestas V52 Wind Turbine through Comparative Test Case Analysis. Energies 2021, 14, 915. [CrossRef]

26. Kim, H.-G.; Kim, J.-Y. Analysis of Wind Turbine Aging through Operation Data Calibrated by LiDAR Measurement. Energies 2021, 14, 2319. [CrossRef]

27. Carta, J.A.; Velázquez, S.; Cabrera, P. A review of measure-correlate-predict (MCP) methods used to estimate long-term wind characteristics at a target site. Renew. Sustain. Energy Rev. 2013, 27, 362-400. [CrossRef]

28. Zhang, M.H. Wind Resource Assessment and Micro-Siting: Science and Engineering; John Wiley \& Sons: Singapore, 2015.

29. Olauson, J. ERA5: The new champion of wind power modelling? Renew. Energy 2018, 126, 322-331. [CrossRef] 